\title{
Influence of Arc Current on Surface Properties and Corrosion Resistance of AlCrN Coatings Deposited by Multi-arc Ion Plating
}

\author{
Sheng Zhu ${ }^{1}$, Yongfa Qin ${ }^{1, *}$, Hui Mei ${ }^{1}$ \\ School of Mechanical Engineering, Yangzhou University, Yangzhou 225127, China \\ *E-mail: qinyongfa@yzu.edu.cn
}

doi: $10.20964 / 2020.06 .44$

Received: 8 February 2020 / Accepted: 27 March 2020 / Published: 10 May 2020

\begin{abstract}
High aluminum-content $\mathrm{AlCrN}(\mathrm{Al}: \mathrm{Cr}=70: 30)$ coatings are deposited with various arc currents using multi-arc ion plating (M-AIP) technique. The relationships between arc currents and coating properties were studied. The microstructures and morphologies of the coatings are tested by X-ray diffraction (XRD), scanning electron microscope (SEM), energy dispersive X-ray spectroscopy (EDX) and surface profilometer, combined with potentiodynamic polarization curves of $3.5-\mathrm{wt} \% \mathrm{NaCl}$ solution. Results show that the intermetallic phase turns to the fcc structure as the arc current increased, and more substrate phases can be observed. As the arc current increased, metal particles and droplets on the coating surfaces are gradually removed, and the surface roughness decreases. Potentiodynamic polarization curves show that the corrosion resistance of the $\mathrm{AlCrN}$ coated samples is obviously improved with the arc current increasing from 120 A to $180 \mathrm{~A}$. The increase of the corrosion potential was about $120 \mathrm{mV}$ and the reduction of the corrosion current with an order of magnitude.
\end{abstract}

Keywords: AlCrN; Corrosion resistance; Arc current; Multi-arc ion plating

\section{$\underline{\text { FULL TEXT }}$}

(C) 2020 The Authors. Published by ESG (www.electrochemsci.org). This article is an open access article distributed under the terms and conditions of the Creative Commons Attribution license (http://creativecommons.org/licenses/by/4.0/). 